\section{Kinetic-kill weapon doubts}

\section{San Francisco}

KINETIC-KILL vehicles, the tiny homing rockets some members of the Reagan administration are counting on for early deployment of a ballistic missile defence, will have a tough time hitting new solidfuel and quick-burning Soviet SS-24 and SS-25 missiles, a new study indicates.

The latest scepticism over 'smart rocks' rises from analysts deep in the ranks of the Star Warriors at the Lawrence Livermore National Laboratory in California.

The conclusions are likely to complicate efforts to convince Congress to allow an early deployment of a missile defence system. They emerged from an analysis published in Livermore monthly magazine Energy and Technology Review by Christopher T. Cunningham, Philip Duffy and Thomas Morgan.

The Livermore trio devised a computer model that simulates the acceleration, speed and accuracy of kinetic-kill vehicles, or $\mathrm{KKVs}$, deployed from polar-orbiting satellites $500 \mathrm{~km}$ up. The Livermore simulation gives the defence 20 seconds to spot ballistic missiles rising through the troposphere, and assumes KKVs can achieve $20 \mathrm{~g}$ acceleration and a velocity of $6 \mathrm{~km}$ per second with a 90 per cent chance of hitting the target. Against today's ponderous liquid fuelled SS-18 and SS-19 missiles, the KKVs "may be effective", the study concluded. The currently deployed Soviet arsenal of 7,000 strategic missile warheads could be 75 per cent destroyed by an armada of $10,000 \mathrm{KKVs}$, and might be stopped entirely by two or three times that many.

However, a solid-fuelled SS-25 is another bird altogether. With its motor burning for just 3 minutes, and a single warhead to deploy, it would be hittable by a satellite-based $\mathrm{KKV}$ for just 3.8 minutes.

Worse for the KKV scheme, the Soviets could alter their rocket nozzles for a faster burn, and deploy their multiple warheads all at once rather than one by one, cutting the time a KKV has to reach the target. "We are very sceptical of the wisdom of relying on the first generation of kinetic kill vehicles to provide any real protection", Cunningham said.

In the heavily politicized atmosphere surrounding the Strategic Defence Initiative, no opinion can be considered disinterested. The Livermore laboratory is one of the bulwarks of research into successful missile shields, but its main job is to refine high-energy lasers, and other exotic weapons - programmes some scientists there see as jeopardized by any expensive, crash programme for early deployment of simpler systems.

Charles Petit

\title{
Museum officials confident Archaeopteryx is genuine
}

\section{London}

OfFicIals of the British Museum (Natural History) this week announced the results of new tests which they say prove that the museum's fossil specimen of the primordial bird Archaeopteryx is not a forgery. The announcement coincides with the opening of an exhibition at the museum, whose subject is the allegations by $\mathrm{Sir}$ Fred Hoyle and others (see below) that the feather impressions on the fossil were forged in the nineteenth century.

The museum staff have used ultraviolet light to reveal which parts of the fossil contain significant amounts of organic material - organic matter fluoresces under ultraviolet light. Only the remains of the bones fluoresce (see figure). Hoyle and the others have alleged that the feather impressions - around the bones of the wings and tail - were added by pressing modern feathers into wet cement laid over a genuine fossil of a featherless reptile. That the feather impressions fluoresce

\section{.. but opponents renew demands for proof}

Those trying to prove that the Archaeoptery $x$ fossil is a fake have already placed on record their belief that the exhibition at the museum is unfair to their case. They have also made renewed demands to be allowed to test more material from the fossil.

The group, which includes Professors Fred Hoyle and Chandra Wickramasinghe, both astronomers from University College, Cardiff, and Professor Lee Spetner, an Israeli physicist, claim that the chemical tests they propose could quickly settle the matter - using minimal amounts of rock. But the museum says all relevant tests have already been carried out, and that none casts doubt on the fossil's authenticity.

In 1986, Spetner was supplied with material, from parts of the fossil separate from the main area of feather impressions. He claims that scanning electron microscopy (SEM) and X-ray spectroscopy tests

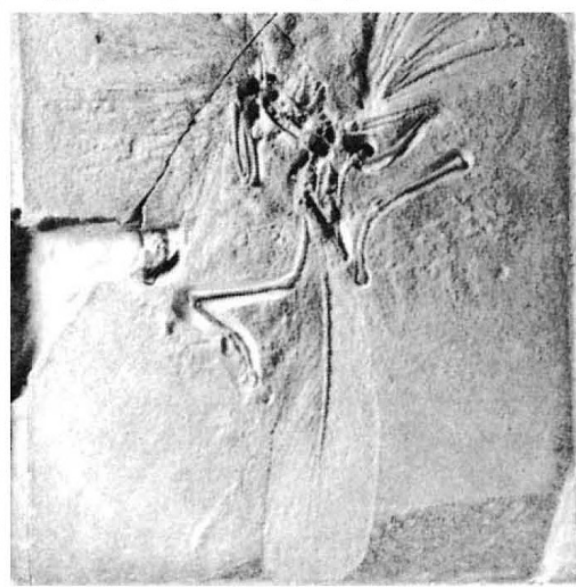

Archaeopteryx (ultraviolet picture on right) - early bird or tarred and feathered reptile? under ultraviolet no more strongly than the surrounding bare rock shows that they are not on a layer of the sort of cement claimed to have been found on material from the slab - ground-up limestone mixed with organic glue.

Dr Angela Milner, curator of fossil birds at the museum, stressed that the new data was only the most recent of several lines of evidence that support the authenticity of the fossil. Dr Alan Charig said museum staff strongly resented allegations of dishonesty and are denying the doubters access to the specimen.

The exhibition sets out to present both sides of the forgery controversy. The centrepiece is a closely guarded display of the museum's Archaeopteryx, together with casts or photographs of the other five known specimens. Although the museum has made it clear that it believes that the fossil is genuine, visitors to the exhibition are challenged to study the evidence and make up their own minds. Giles Courtice

revealed differences between the parts of the fossil bearing feather impressions and other parts of the stone slab (see Nature $324,622 ; 1986)$. If the feather impressions were added in the nineteenth century to a real, featherless fossil, such a difference might be expected. But the museum says it is probable that one of the samples happened to include traces of a substance put on the fossil to preserve it.

The forgery theory, spelt out in a recent book by Hoyle and Wickramasinghe (see Nature 324, 185; 1986), has received little support from biologists, palaeontologists or geologists. But Hoyle sees the museum's refusal to supply the doubters with more material as evidence of an "unscientific" unwillingness to settle the issue. The museum refuses to risk damage to the specimen for tests they consider unnecessary.

Giles Courtice

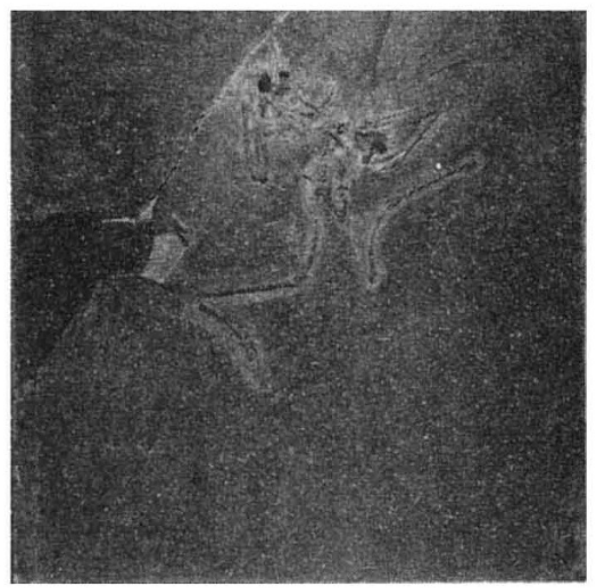

